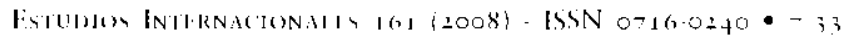

Institute de Estudios Intermacionalen. Iniversidad de (hile

\title{
La crisis del canal de Beagle
}

\author{
The Beagle Channel Crisis
}

\author{
Jon Marco Church
}

\section{Q Resumen}

In cesta Navidid, se cumplen treinta años de la crisis del camal de Beagle. La presente contribucion reconstruye esta historial, desde sus comienzes en 1977 a la amemazal de guerril, la mediaciom vaticana y fundamentalmente la ratificicion por Argentina del Tratade de Pazy Amistad, e'n 1984. Rechazando faciles antalengias on la guerra de las Malvinas, se retuta la reducion de la crisis a una maniolsta populista de

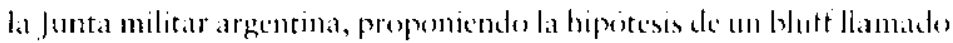
pere (hile con clencurso del Vaticano. I legamos al traltado culazinde las dinimicas prepials de la mediacion con el contexto mis amplio de la transición argentinal y de la coyuntura connomica. Esta reconstrucicion se funda tante en material publicado como en entrevistas incitias.

Palabras chavl: Argentina, (hile, Beagle, crivis, negocialcones

Investigador, representante de la Academia Furopeia de Bolzano en Paris, <jon-maroo.

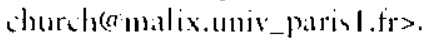

Recibide et 29 de septicmbre de 2008 ; aceptidelo el 6 de octubre de 2008

F.l autor agradece particularmente al centre of l atin American Studies de la l laiversidad de Cambridge, Reino Unido, a Queens" College de la misma ciudad, al hotituto de fortudion Internacionales de la Inesersidad de Chile y al presidente de la facultad de

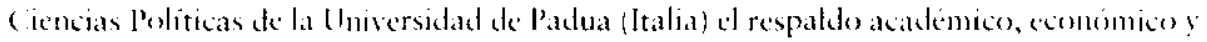
logistico a este proyecto de investigacion. 
Abstract

This (hristman we commemotate the thireieth anniversary of the Beagle Chandel criss. l hiscontribution recomstructs this piece of history, from its beginning in 1977 to the menace of war, the Vatican mediation and finally the ratification of the Treaty of Peace and loriendship by Argentina in 1984. Dismissing simplistic analogies with the Falklands War, the reduction of the crisis to a populise manoesure of the Argentinc Military Junta is refuted and the bypothesis of a bluff called by (hile with the supporo of the Vortican is proposed. The ereaty is approalded intertwining the mediation s dynamics with the broader context of the Argentine tramsition and the economic compuncture. This reconstruction is based an puhlished material as well an on hitherto unpuhlished intervicus.

K1.Y Wornos: Argentini, Chile, Beagle, crisis, megotiations 
LOS COMIENZOS DE LA CRISIS

Lo peor wino en 1978, cuando Argentina pudo impunemente desconocer un laudo arbitral y amenazar una guerra.

Fermandois, 1991: 445

De febrero de 1977 a enero de 1978

Desde comienzos de 1977, Chile y Argentina presintieron que el laudo arbitral sobre el Canal de Beagle -relativo a la soberania de las Islas Picton, Lennox y Nueva- sería favorable a Chile'. El gobierno argentino anunció

Descle los incicios del diferendo hasta fines del siglo XIX, Chile siempre fue partiatario de una solución arbitral a la disputa sobre df Canal de Beagle, no solo porque era más probable que tuviese derecho a las islats sino tambien debido al carácter legalista de su política interior y exterior. En 1902 , cono consecuencial de la crisis de la Punla de Atacama, en 1898, Chile y Argentina habian suscrito un Tratado Cieneral de Arbitraje. El primer acuerdo para resolver a) litigio mediante arbitraje tuvo lugar en 1915, pero soloen 1970, bajo el golvierno de Allende, Chile persuadió a Argentina, yue aún se encontraba bajo el régimen militar de Ievingstom, yue se pidiera la mediación de la Reina de Inglaterra. Fl acuerdo de ambos países al respecto fue formalizado en 1971, épocia en yue el progresista lanusse cra presidente de Argentina. En el mareo de una serie de acciones amistosas que promovieron el acercamiento entre los dos páses, varios acuerdos de conperacion en diferentes áreas, tales como trabajo, silud, se anexaron al compromiso arbitral. En 1972, Buenos Aires y Santiago acordaron renovar el lratado Ciencral de Arbitraje de 1902, pero pocos meses después, Argen- de inmediato que no aceptaría un laudo que entregase todas las islas a Chile. Sin embargo, los litigantes no tenían mucho de qué sorprenderse ya que varios estudios anteriores sobre el probable resultado de un arbitraje internacional eran favorables a Chile (Mares, 2001: 1.34).

El tribunal arbitral, presidido por el juez británico Gerald Fitzmaurice deliberó en febrero de 1977; la Reina pronunció el laudo en abril de ese año; y el 2 de mayo se comunico oficialmente la decisión a las partes (L acoste, 2003: 418). El laudo decretaba lo siguiente: "Las islas Picton, Nueva y I.ennox, así comolos islotes y piedras circundantes, pertenecen a la República de Chile». El 3 de mayo Argentina rechazó el laudo, declarando que: "ningún compromiso obliga a cumplir apuello que afecte intereses vitales de la Nación o que perjudique derechos de soberania que no hayan sido expresamente sometidos a la decisión de un árbitro»².

Argentina no acusó al Reino Unido de otorgar preterencias a Chile durante los procedimientos ni después del laudo. En los años setenta, bajo el gobierno laborista, las relaciones entre Chile y el Reino Unido no estuvieron en tan buen pie como después de 1979,

tina tuvo la intencion de rechazarto para impedir el arbitraje del Beagle, pero ya cra demasiado tarde para cletener el procedimiento (Award, 1977; Yofre, 200)( P'astor, 1996: 263). Cabe señalar que este se calracterizó por largos testimonios, que duraron hasta julio do 1977.

2 la (opinión, 4 de mayo de 1977. 
con Thatcher'. A lo largo del procedimicnto, Argentina atacó al Reino Unido alegando un supuesto deterioro de las relaciones bilaterales y propuso retirarse del arbitraje aduciendo que el árbitro se había convertido en una de las partes, e incluso propuso el retiro del Reino Unido por haber causado el empeoramiento de las relaciones bilaterales (Mares, 2001: 135). De acuerdo con esto, el Congreso argentino votó unánimemente en favor de suspender el proceso. Argentina aprovechó la ocasión para acusar al Reino Unido por la cuestión de las Islas Malvinas, ya que desde 1966 venía insistiendo en la descolonización de las islas. Las pretensiones argentinas recomenzaron en 1977 -cinco años antes de la ocupación de 1982- hasta que los servicios británicos forzaron al gobierno a enviar una flotilla guerra a la zona ${ }^{4}$. Dehído a esta situación, Argentina acusó al Reino Unido de manipular el laudo, entre otras razones para desviar la atención de las Islas Malvinas al Canal de Beagle. En todo caso, es improbable que el gobierno británico tuviese esa intención.

Las relaciones se habian deteriorado por la situlición de los derechos bumanos t'n (hile. I.os británicos negaron la venta de armas a (hile, mientras que no las suspendieron a Argentina. Cubillos recuerda que en 1978 al Reino Unido llegó incluso a retirar su embajador en Chile, Reginald Scoonde, como reacción por cl caso de Shcila Cassidy (Tapia, 1997: 279).

Sobre las negociaciones actra de las Malvinas en el periodo 1978-1980, ver Pastor (1996: 270-281) y Freedman (20) 0.5$)$.
Segun el Foreign and Commonwealth Office, al parecer la mayoría de los funcionarios simplemente ignoraban la existencia de las Malvinas y en los archivos nacionales británicos no se encontraron indicios de manipulación (Freedman, 2005).

¿Por qué Argentina rechazó el laudo? Infante (1984, 345-355) propuso dos explicaciones: la primera de ellas de carácter geopolitico, la segunda ética y política. Sin embargo, a nuestro juicio pueden identificarse varios factores más concretos que condujeron a esta decisión: el propio laudo, la defensa, la economía y la política interior.

Primero, en lo que se refiere al laudo, los argentinos consideraron que no era equilibrado, ya que dejaba todas las islas a Chile y por ende, como una decisión que atropellaba el llamado principio bioceánico de "Argentina en el Atlántico y Chile en el Pacífico»", ya

El principio bioceánico tiene como origen el Iratado de Límites de 1881. Chile obtuvo la neutralidad argentina en la Guersa del Pacifico a cimbio de un millón de $\mathrm{ki}$ lómetros cuadrados de Patagonia chilena. Chile también estuvo de acuerdo con el principio de "la linea de las más altas cumbres que dividen las de aguas" para delimitar los Andes chilenos y argentinos, asi como con el de "Argentina en el Atlíntico y Chite en el Pacífico" con el fin de distinguir el mar de los dos países vecinos (Rojas-Nedrano, 1979; Iacoste, 2003: 104). La Ciucra del Pacifico duró de 1879 a 1884 y fue un acontecimicnto funcional de la historia chilcna, ya que en ella Chite se defendio de la agresión peruana y boliviana. La guerra marcó profundamente la psicologra colectiva chilena, ya que contrihuyó al alto prestigio de los militares, a 
que permitía a Chile el acceso al Atlántico, y esto desafiaba el orgullo nacional argentino (Videla Cifuentes, 2008).

Segundo, en cuanto a la defensa, los argentinos percibieron el laudo como una amenaza estratégica y geopolítica, debido a que temían que en el futuro los chilenos, yue consideraban "expansionistas", intentaran acrecer sus pretensiones marítimas en el Atlántico y en la Antártica. Esto habría tenido efectos nefastos para sus intereses cconómicos en el área, por demás rica en pescado, minerales y petróleo (Garrett, 1985: 82-86).

En su libro Geopolitica, Pinochet (1974: 16.5) escribió: "el país más fuerte militar o económica, diplomática o demográficamente, tendrá ventajas en los litigios de fronteras". En este caso, considerando las «leyes férreas de la geopolítica" y la paridad teórica entre las dos armadas, el país más fuerte era Argentina. Si Chile hubiese conseguido la soberanía sobre las islas, la marina argentina -bajo el "duro" almirante Massera- lo habria impedido pese a las ventajas teóricas de la armada chilena en el Estrecho de Magallanes. Para la marina argentina, había que detener a los chilenos antes de que llegasen a la capital federal.

la profunda desconfianza en los vecinos del norte y a la paranosia de ma guerra simultánea contra los tres vecinos ( "HV 3 "hipótesis vecinal 3), condenando a (hile al mismo destino de l'aringuay después de la Civera de la Triple Alianza (186.5$70)$.
No cabe duda que la razón de existir de los militares es la guerra, por lo que los términos estratégicos y geopolíticos son de uso común (Infante, 1984: 345 350). Los años setenta fueron años de oro para el pensamiento geopolítico sudamericano (Pinochet Ugarte, 1974; Gomez Rueda, 1977; Child, 1979; Kelly-Child, 1988) y los militares del Cono Sur miraban sus relaciones recíprocas a través de un cristal geopolítico.

Tercero, por lo que toca a la dimensión económica, Garrett (1985, 82-84) comentaba:

Cada gobicruo tenía mucho yue ganar al mantener su posicion. Argentina estimaba cue el área del (anal de Beagle podia representar tres mil millones de dólares en pescado, minerates y petróleo; mientras que chile esperaba satisfiace el $4.5 \%$ de su necesidades de petróleo... una vez que se instalaran las plataformas pertoradoras".

A esto se agregaba también la cuestión del territorio antártico correspondiente, donde -si bien en las dos décadas precedentes las relaciones entre ambos paises habian sido de relativa cooperación-en los años setenta la mayoría de los países seguía especulando sobre los recursos minerales existentes

"El control del área era particularmente importante debido a que del lado del latacifico la anchura de la plataforma continental de Chile-donde se realizan las perforaciones petroliferos offshore- es de solo 20 o 30 millas, mictstras que en la región del Canal de Beagle, clla se cxtiende por aproximadamente 200 millas" (Carrett, 198.5: 82-84). 
bajo los hielos antárticos. E1 Tratado Antártico de 1959 había "congelado" toda disputa hasta 1991, cuando la mayoría de los países comenzaron a valorar sus pretensiones y pidieron la renegociación del tratado (Pinochet de la Barra, 1999; Guzmán, 2004). En 1977, Chile y Argentina se asentaban después de los golpes de Estado de 1973 y 1976, respectivamente. La mayoria de los países se estaban recuperando de la primera crisis petrolera mundial de 1973 y el mundo estaba al borde de una segunda crisis en 1978-1979. La razón por la cual ambos países buscaban recursos escasos como minerales y petróleo se explica por sí sola, no solo desde una perspectiva de seguridad nacional, sino también debido al riesgo de escasez por crisis -o bloqueos-internacionales imprevisibles.

Cuarto, en lo respecta a la política interior, a menudo se ha partido de la base de que el gobierno militar argentino utilizó ambas crisis (Beagle y Malvinas) para mantener el apoyo popular, ya que ayudaban a formar un sentido de unidad nacional (Turolo, 1996). En Argentina, los militares alertaron a la población y promovieron una "psicosis de guerra". Por otra parte, en 1977 la economía evolucionaba en forma relativamente favorable, el proceso de reconstrucción nacional consiguió "estahilizar" el país, las masas populares ignoraban los excesos de la "guerra sucia" y Argentina estaba en punto de ser anfitrión y de ganar la copa del mundo de fútbol. Por todas estas razones, la tesis populista no parece del todo adecuada para el caso argentino. Por el lado chileno, el régimen pinochetista no tenía nada que perder pintando a Argentina como agresor y convirtiéndola en chivo expiatorio. Sin embargo, ni Pinochet, ni las fuerzas armadas, ni la prensa lo hicieron, o de lo contrario lo hicieron dentro de un círculo muy pequeño, que no alarmó a la población (Tapia, 1997; Infante, 1984). Por estas razones, la tesis nacionalista tampoco parece aplicarse al caso de Chile.

Mientras que Argentina rechazó el laudo, Chile lo aceptó de inmediato. El 4 de mayo de 1977, Argentina propuso negociaciones bilaterales para resolver todos los diferendos fronterizos - no solo la cuestión del Canal de Beagleintentando llevar la disputa del nivel jurídico al político. Entre jul io y octubre, los dos países realizaron negociaciones bilaterales en Santiago: el general Villegas, por Argentina y el jurista Phillipi, por Chile, encabezaron las delegaciones respectivas (Garrett, 1985: 93; EscudéCisneros, 1998-2003). Tras el fracaso de las negociaciones Villegas-Philippi, los esfuerzos bilaterales continuaron con una serie de misiones diplomáticas chilenas en Buenos Aires. El general Toro Dávila lideró la primera de ellas y el general Contreras ${ }^{7}$ la segunda. El Almirante Torti condujo la primera misión argentina y propuso modificar el Tratado de 1881 y dejar todas las islas a Argentina (Infante, 1984: 343). La

El mismo Cieneral Mantuel Contreras, cutonces jefe de la DINA, profundamentc involucrado en la represión y en la operación Cónder. 
"linea Torti" era claramente favorable a Argentina y no podía ser el punto de partida para los negociadores. El hecho de que las tres primeras misiones en Santiago fueran argentinas pareció sugerir que, al comienzo, Argentina intentó enfrentar la posición chilena. El hecho de cue las dos últimas fuesen misiones chilenas en Buenos Aires sugiere que Chile estaba defendiendo su posición con urgencia. Entre julio y octubre, Argentina y Chile invirtieron sus posiciones relativas.

Mientras tanto, ef 14 de julio la Junta Militar chilena promulgó el Decreto Supremo 216, mediante el cual Chile implementaba unilateralmente el laudo. La crisis escaló rápidamente: Bolivia, aliado tradicional de Argentina -esperando recuperar el acceso al mar-, junto con Perú -enemigo histórico de Chilerompieron relaciones diplomáticas con Chile. Con las negociaciones estancadas, Argentina enviaba las primeras señales a Chile de que consideraba que la fuerza era militar era una opción. En septiembre, movilizó parte de su flota e incrementó sus movimientos en el área del Estrecho de Magallanes.

Hasta fines de 1977, los dos regímenes conservaban mucho en común. No solo la forma de gobierno era análoga, sino también sus objetivos eran similares: guerra interior contra la subversión y el terrorismo, hasta eliminarlo; gucra exterior contra el comunismo, mientras seguían perteneciendo al movimiento de los no-alineados; modernización y liberalización de la economía; perspectiva conservadora respecto de las relaciones entre clases sociales. Hacia fines de 1977, en ambos países prácticamente habia terminado la guerra contra la subversión; la operación Cóndor (Paredes, 2004; Seoane-Muleiro, 2001; Miranda, 1989) habia perdido impulso , y la época de distensión había mejoradolas relaciones este-oeste. los dos países también habian negociado una propuesta que daba acceso a Chile a los puertos argentinos y viceversa, a fin de facilitar el comercio chileno en el Atlántico y el acceso de Argentina al Pacífico y a los mercados asiáticos. Según una fuente militar argentina de alto nivel, inmediatamente antes la crisis del Beagle, Pinochet pidió a Videla que eligiera dos entre cuatro puertos chilenos. Las negociaciones tracasaron debido al diferendo territorial.

Los militares argentinos pensaban crear su propio partido político y convocar a elecciones democráticas. En esa época, creyeron que tenían posibilidades de ganar las elecciones debido a lo que ellos percibían cómo un relativo éxito del proceso (Turolo, 1996: 111-

Fintre el 13 y el 15 de diciemhre de 1976 , los " representantes de todos los paises yuc participaban a la operacion Condor se encontraron en Bucnos Aires para discutir la situación creada por el caso Letelicr", asesinadoen Washington el 21 de septicmbre de 1974 fle: Monde diplomaticpue, mayo 2001). Este encuentro parece marcar una fecha critica después de la cual la operacion cóndor desaparecio del marco de las relaciones politicas del Como Sur Se recuerda que uno de los primeros hechos de esia operacion fue el asesinato del General Cartos Prats en Buenos Aires, el 30 de septiembre de 1974. 
113). Si esta opción era sustentada por Videla, ella era refutadia, entre otros, por el Jefe de la Marina, Massera". Este ejemplo revela cómo los conflictos y la rivalidad al interior de las fuerzas armadas y entre las distintas ramas, especialmente entre la Marina y el Ejército, debilitó la posición negociadora de Argentina antes, durante y despućs de la crisis, hasta los últimos días del gohierno militar, en 1983. Según Mares, durante la crisis, Videla corrió el riesgo de encontrarse en minoría al interior de la Junta (2001: 144).

Las amenazas argentinas de recurrir a la fuerza militar a fines de 1977 , en cierto modo moderaron, la posición chilena, hasta aquel momento inflexible; $y$ persuadieron a los chilenos de que la crisis era seria, por lo cual se enviaron las misiones de Toro Dávila y Contreras. A pesar de que Contreras conocía bien a los argentinos, las misiones fracasaron. Llegó el tiempo de la diplomacia presidencial.

En febrero 1978, Nassera acusó a Videla y al ejercito, de falta de nacionalismo y de no respetar los derechos humanos (le Monde diplomatique, abril 1978).
Continuación de la crisis

Del 19 de enero al 2.3 de diciembre de $1978^{\prime \prime \prime}$

F. 19 de enero de 1978, los presidentes Videla y Pinochet se encontraron en la base aérea de Plumerillo en la provincia de Mendoza, para celebrar el primero de dos eventos clave: las cumbres de Plumerillo y de Puerto Montt. En el primero, Videla confirmó el rechazo del laudo. Pinochet le advirtió que corría el riesgo de transformar el área del Canal de Beagle en zona de conflicto y que esto contribuiría a desacreditar a ambos países a nivel

Sohre este perícdo Pastor (1996), Menéndez (Menéndez, 1981: Tapia, 1997), Turolo (1996), Escudé y Cisneros (1998. $2003)$ han realizato detalladas reconstrucciones del punto de vista argentino; y por su cuenta Tapia (1997) hizo lo mismo desde la perspectiva chilena. De particular interés son las entrevistas con tol general retirado argentino Nenéndez y con el entonces canciller chileno Cubillos. Si la versión académica de Escudé y Cisneros, Historia general de las relaciones exteriores de la República Argentina, centra más la atención en el proceso de toma de decisiones de Argentina, adhiriendo a los análisis de Princen (1988) y Russell (1990), una versión mas accesible de Turolo, 1)e Isabel a Videla, ofrece perspectivas interesantes sobre la visión de los militares, si bien algunos detalles bistóricos suelen parecer aproximativos. Nares en su Violent l'cace (2001, ch. 6), y Garrett con su articulo "The Beagle (hannel l)ispute, Controntation and Negotiation in the Southern Cone" (1985), presentan úriles puntos de vista, especialmente para lectores extranjeros poco familiarizados con la historia y la política del Cono Sur. 
internacional y podía convertirse en causa de una posible guerra derivada de un incidente fronterizo. Videla aseguró que habían considerado atentamente todos los riesgos y que las negociaciones politicas eran la única solución posible (Turolo, 1996: 115). Respondiendo a las preocupaciones de Pinochet, Videla propuso la creación de dos comisiones: la primera tendría 60 días para estudiar y crear un mecanismo que evitara incidentes fronterizos, mientras que la scgunda debía encontrar una solución política en el plazo de 180 días.

De súbito Chile parecía estar en una posición dificil: cra estratégicamente inferior y no era capaz de trascender el nivel jurídico, en cambio Argentina fue firme y agresiva. Sin embargo, Chile y no Argentina promovió los últimos esfuerzos diplomáticos: Pinochet $-y$ no Videla- había insistido la necesidad de evitar una guerra entre las dos naciones. A final del encuentro, Pinochet de pronto dibujó un mapa del área, trazando una línea vertical que dividia las islas Evout y Barnevelt.

La propuesta de Pinochet era similar a la «línea Torti» y era extremadamente favorable a Argentina, por lo que Videla aceptó súbitamente el dibujo y se mostró entusiasta. La estrategia de Argentina consistía en amenazar a Chile con una acción militar: no una simple ocupación de las islas, sino una verdadera invasión a Chile. Pinochet cometió el error de desviar su posición inflexible de los meses anteriores, al dar mucha libertad de acción, lo que intensificó la amenaza de invasión. Este gran error fue uno de los factores que llevaron a los dos países al borde de una guerra total (Bignone, 1992: 50-51; Passarelli, 1998: 52-53; Turolo, 1996: 114-117)".

El 25 de enero de 1978, inmediatamente antes de que entrase en vigor el laudo, Argentina lo rechazó de manera definitiva y declaró oficialmente que era «insanablemente nulo»'?. Al día siguiente, Chile reafirmó que el laudo era "obligatorio y no susceptible de apelación". ¿Por qué Chile no pudo recurrir unilateralmente a la Corte Internacional de Justicia de Ia Haya, considerando que el Tratado General de Arbitraje de 1972 le daba el derecho de hacerlo? Según Fscudé y Cisneros (1998-2003), los chilenos no temían los argumentos para recurrir a I a Haya debido a que los argentinos habían declarado el laudo nulo, aunque técnicamente no lo habían rechazado. A principios de 1978, la cumbre de Plumerillo y la declaración de nulidad del laudo no eran los únicos elementos que deterioraban las relaciones bilaterales: la prensa argentina había empezado una intensa campaña contra las pretensiones chilenas, acusando al país trasandino de expansionismo ${ }^{13}$.

"Fista versión dele encuentro de Plumerillo es contirmada por fuentes militares chilenis.

12 Véase también Le Monde diplomatique, enero de 1979.

:3 No es fácil juzgar si era el golvierno argentino el que maniobraba a la prensa. lis cierto que el gobierno militar argentino persiguió y ejecutó at varios periodistas, especialmente durante los primerers des años del proceso (Seranc-Mlukiro, $2(y))$ ). 
Fl 4 de mayo, los dos presidentes se encontraron en Chile, precisamente en Puerto Montt, para formalizar las comisiones binacionales y discutir la propuesta de Pinochet. Este dijo de inmediato a Videla: "Ese dibujito, rómpalo, porque no me lo aceptan". ¿Por qué los chilenos rechazaron la propuesta de Pinochet? Turolo (1996: 115-116) sugiere que Pinochet tenía "dos caras" -hombre aparentemente respetable, pero realmente mentiroso y engañador-, o bien no siempre tenía el control de la Junta. En teoría, Pinochet gozaba de una absoluta unidad de mando ${ }^{1+}$ (Tapia, 1997: 272) y se encon-

También se ha demostrato yue el gobierno aprovecho la escasez de cétulosa para controlar indirectamente varios periódicos, como se desprende del escíndalo Papel Prensa de 1979, cue involucró a la Nacion, Clarín y la Razón, entre otros. Por otra parte, una mirada a La Nación de Buenos Aires de la épocia milestra cierra superficialidad en la cobertura inernacional y una propensión al cscándalo, especialmente cn las relaciones con Brasil y Chile (I avopa, 1995; Knudson, 1997; (ox, 1980). En consecuencia, cl alarmismo de la prensa argentina podía facilmente depender de factores intrínsecos a li cultura periodística argentina y nos solo de la intervención directa o indirecta del gohicrno. El papel de la prensa chilena da la impresión contraria: si bien los periodistas a menudo tenían conciencia de la gravedad de la crisis, la prensa evitó alarmar a la población (Tapia, 1997).

id F.n realidad, al interior de la Junta militar chilena existían problemas y rivilidades, aunclue menores que cn la Junta argentina. Entre marzo y julio de 1978, el general de aviación Gustavo Leigh intentó una maniobra parcida a la de Massera pocos meses antes en Buenos Aires (supra). Fl traba en una posición de mayor fuerza respecto de Videla, que tenía que luchar al interior de una Junta pluralista. ¿Por qué ante los ojos de los argentinos Pinochet no pudo reconsiderar su propuesta, junto a otros militares y juristas, y decidió rechazarla y entregar a otros la responsabilidad? Chile había ganado el laudo y Argentina lo había rechazado, pretendiendo tener la soberanía sobre todas las islas y amenazando de una invasión. Chile puso sobre la mesa tanto la fuerza moral del laudo cuanto la fuerza económica de un posible embargo internacional, que habría apoyado al país que defendía -Chile-, y no al que agredía-Argentina-así como su fuerza militar. Chile llamaba al bluff.

El encuentro procedió y se formalizaron las comisiones. Los argentinos, optimistas del encuentro, consideraron que a través de la segunda comisión, encargada de encontrar una solución politica, habían conseguido llevar el debate del nivel jurídico al plan político. Sin embargo, en un comunicado de prensa entregado después de firmar el Acta de Puerto Montt, Pinochet pronunció un discurso preparado previamente por un jurista en que propugnaba inflexiblemente las pretensiones jurídicas de su país y dejaba frustrados a los argentinos, con la impresión de haber sido traicionados. Sorprendido, Videla improvisó una respuesta, en la que se acercaba a la posición de los "halcones"

resultado fuc que leigh y dieciocho oficiales de aviación de alto nivel fueron llamados a retiro. 
entre los militares (Pastor, 1996: 263; Escudé-Cisneros, 1998-2003). Fue entonces que la Junta argentina amenazó a Chile con una acción militar, buscando forzar al amenazado a desviar su posición inflexible.

En tel mes de mayo, inmediatamente después de Puerto Montt y del discurso de Pinochet, la Junta argentina asistió a una manifestación especialmente imponente de la fuerza Aérea y más tarde ese mismo mes, el Ejército y la Aviación organizaron expediciones masivas en el sur del pais. Durante el verano, prosiguieron las negociaciones politicas en el seno de la segunda comisión, pero al aproximarse el otoño, Chile fue inflexible y mantuvo su posición legalista, mientras que Argentina estaba cada vez más determinada a intervenir manu militari. Especialmente la Marina consideraba que la cuestión correspondía a su competencia y creía poder resolverla fácilmente con un golpe de mano (Pastor, 1996; Escudé-Cisneros, 1998-2003).

En septicmbre, Argentina empezó a hacer ejercicios de oscurecimiento tanto en las provincias como en la Capital Federal, con el fin de preparar a la población para un conflicto y alimentar la psicosis de guerra ${ }^{\prime}$. Pinochet nunca

is Cubillos pensaba: "Lira tan ridicula la forma en que Argentina se preparaha para esto... crearon la mística de guerra... ellos sabian que los aviones de combate nuestros no podían despegar de (hile, llegar a Buenos Aires, bombardear Buenos Aires y regresar. Tendrían que haber aterrizado en Fsciza, eso t'ra ridiculo". (Tapia, 1997: 270). Veanse tambien las recién publicadas memorias del general Videla cifuentes quiso ni necesitó alertar a la población civil: "el chileno no necesitaba que le hubiesen hecho propaganda un año antes para salir a pelear y defender su territorio, el chileno reacciona inmediatamente" (Tapia, 1997: 271).

En octubre, la crisis estalló otra vez. La preparación para la guerra fue sustituyendo gradualmente las negociaciones políticas. La mayoría de la vías de comunicación transandinas fueron interrumpidas y se cerraron casi todos los pasos de montaña ${ }^{16}$. Chile puso minas a lo largo de la frontera y los dos países reactivaron sus sistemas de alianzas ${ }^{\prime}$. Entre el 10 y el 20 de octubre, el Jefe del Estado Mayor de las fuerzas armadas chilenas, general Washington Carrasco, visitó Brasil; el 12 y 13 , altos oficiales de Argentina, Perú y Bolivia se cncontraron en La Paz; el 20, Argentina envió una misión a Asunción. El 25, Videla se entrevistó con Pereda ${ }^{18}$ en Yacuba (Bolivia), y el mismo día, Argentina firmó un acuerdo

(2008), antiguo subsectetario de relaciones exteriores y jefe negociador chileno en época de la mediación papal en el conflicto (intra).

In A memudo los pasos se cerraron con piedras, por lo cue las calles ya no temían razón de ser. Por razones de seguridad la mayoría de los pasos fueron declarados "secretos de listado"y permancierom cerrados hasta los años novental (L acoste, 2003). El único yue yuedó abierto durante Jos anos ochenta fuce de (risto Redentor $y$ el tunel que conecta Santiago con Méndoza.

1: Le Monde diplomatique, enero de 1979.

ix Juan l'ereda Asbún, presidente de Bolivia hasta el 24 de noviombere de 1978. 
de cooperación nuclear con Perú. Por otra parte, una misión militar brasileña visitó Chile. Hacia fines del mes, el sistema tradicional de alianzas, que se remontaba a la Ciuerra del Pacífico, estaba reactivado: Argentina, Perú y Bolivia por un lado; Chile, Brasil y Ecuador por el otro, Paraguay y Uruguay neutrales.

Fl 2 de noviembre terminó el mandato de la segunda comisión mixta y no se llegó a ninguna solución política (Memorias, 1978: 447), marcándose así el final de las negociaciones formales y llevando a la movilización general en Argentina. Al día siguiente, Pinochet envió un telegrama, que fue publicado en la prensa argentina, en cl que sugería "la mediación por un gohierno amistoso, en lugar de renovar las negociaciones bilaterales que se hahían demostrado inuitiles" (Mares, 2001: 147).

En noviembre, la situación estalló. Chile estaba "dispuesto a aceptar el Papa como mediador", insistiendo en la inalterabilidad del laudo. Los argentinos dieron la bienvenida a la propuesta chilena de reabrir negociaciones políticas más favorables a Argentina, aunque al mismo tiempo se mostraron escépticos sobre la mediación papal: "a los uniformados los aterraba la posibilidad de que el Sumo Pontífice hiciera pública una opinión contraria a la posición argentina. ¿Cómo rechazar una opinión semejante viniendo de quien vendría?" (Turolo, 1996: 119)

A principios de diciembre, la paranoia de la guerra recobró impulso en Argentina. El 11 del mes, Pastor y Cubillos, los dos ministros de rclaciones exteriores ${ }^{14}$, se reunieron en Buenos Aires y llegaron al acuerdo de que el Papa sería el posible mediador y de que había que mantener los principios de Puerto Montt; sin embargo, no concordaron respecto de los principios para delimitar el Beagle. Pastor lamentaba la total intransigencia chilena (1996: 264). Al parecer, los chilenos tenían informaciones de buena fuente sobre Argentina, en especial sobre sus planes de guerra y decisiones ${ }^{20}$. Cubillos había escuchado voces de la Secretaría de Estado del Vaticano, que aparentemente estaba muy bien informada sobre ambos lados, acerca del plan de uguerra total" de Argentina, también conocido como "Operación Soberania" (Tapia, 1997: 134).

El plan de guerra argentino consistía en que mientras la Marina enfrentaba a sus adversarios en el Estrecho de Magallanes y las fuerzas aéreas destruían los abastecimientos vitales y las lineas de comunicación de Chile, el ejército,

Carlos Washington Pastor fuc canciller argentino de noviembre de 1978 a 1981 ; Hernán Cubillos, fuc su homólogo chileno de 1978 a 1980 .

2" Confirmado en entrevistas reservadas con fuentes chilenas dignas de crédito. Argentina y Chile tienen una larga historia de espiomaje recíproco. En los años treinta, el propio joven l'crón espiaba a los chilenos cuando era agregado militar de la embajadil argentina en Santiago. A lo fargo de la historia, ambos países periódicamente han cncontrado espias en sus respectivos territorios (Escudé-Cisneros, $1998-2003)$. 
al mando del General Menéndez, debía cruzar los Andes para ocupar Santiago y posiblemente Vialparaíso en una operación de Blitzkrieg (Turolo, 1996; Tapia, 1997).

Menéndez comentó: "En seis horas estamos en Santiago, tomamos champaña ell La Moneda y después nos vamos a orinar a Valparaíso" (Lacoste, 1998: 12.5). Sobre los planes chilenos Pinochet comentó:

Si huhiera estallado la guerra, Chile pretendía, si cra posible, llegar hasta Bahía Blanca y de ahí cortar todos los pasos al sur. Yo tenía 10.000 hombres ahí, en el sur. [Yo advertí a] Videla: " Mira, la guerra no será allá (en el sui), como dicen ustedes... será descte Arica, desde Sapaleri, hasta el cabo de Hornos. la guerra es total... Untriunto chileno sobre la Argentina hubiera sido muy difícil, y se hubiera tratado de una guerra de montonera, matando todos los días, fusilando gente... y al final, por cansancio, se habria llegado a la paz... No fumos a la guerra, pero si hubiéramos entrado en ella nos habriamos empeñado por todos los medios y a to mejor no nos habría ido tan mal. Me habrian levantado una estatua, que es a lo que aspira todo militar ${ }^{2.1}$.

El 12 de novicmbre, para poner fin a la intransigencia chilena, los argentinos decidieron tomar las islas (Mares, 2001). El mismo día, el Papa envió un telegrama, publicado en la prensa, dirigido a Videla y Pinochet, en que les pidió hacer los mayores esfuerzos por encontrar una solución pacífica

¿ Clarin, 25 de noviembre de 1999. a la crisis. F.jecutando la decisión del 12, el 14 de noviembre Videla dio la orden de invasión inmediata, antes de encontrarse con el nuncio apostólico, Pio Laghi ${ }^{22}$. Videla "le informó que había dado órdenes de ocupar las islas la semana siguiente" (Mares, 2001).

Videla insistió en que era necesario evitar la guerra y pareció ser una palomita blanca en comparación con los Comandantes en jefe de las tres ramas de las fuerzas armadas: Viola al frente del Ejército, Agosti de las fuerzas aéreas y Lambruschini al frente de la Marina. Turolo señala que la situación de los comandantes era más difícil (1996: 120), habían dado ordenes de atacar y se estaban arriesgando a dar una contraorden, con lo cual podían perder toda credibilidad. En el caso contrario, la gloria habría sido de los Lambruschini y Menéndez. (Menéndez, 1981; Tapia, 1997: 248-251).

Según Mares (2001) días antes, con el fin de ejercer presión sobre Chile, Videla y Pastor comenzaron contactos diplomáticos con Estados Unidos, la Unión Sovićtica, algunos países europeos, el Vaticano y las Naciones Unidas. Las respuesta inicial del Pentágono fue lenta, debido a la situación de los derechos humanos y al bloqueo de armas. Al principio, los Estados Unidos se limitaron a promover el recurso a los buenos oficios de la Organización de

:2 F.mbajador del Vaticano en Bucnos Aires, 1974-1980. Para una crítica del papel de la Iglesia católica en Argentina, véase por ejemplo "Represión c iglesia en Argentina" (1987), en Principios, n. 28, pp. 17-27. 
los Fstados Americanos (Pastor, 1996: $263)^{23}$. El Embajador de Estados Unidos en Buenos Aires, Raúl Castro, había enviado varios informes de alerta y comenzó a contactar a los sectores más belicistas, concluyendo que los Estados Unidos debían intervenir con la máxima urgencia (Tapia, 1997: 234-239)24. Entre el 15 y el 16 «el Departamento de Estado, la Casa Blanca y el Congreso aclararon que cualquier uso de la fuerza armada sería condenado por los Estados Unidos y sus aliados; el gohierno de Estados Unidos pidió al Vaticano actuar rápidamente" (Mares, 2001).

El "día D" y la "hora $\mathrm{H}$ " eran el 22 a las 22 , una noche de verano austral. Ambos lados preparaban la guerra. Los chilenos esperaban una guerra larga, mientras que los argentinos confiaban en una victoria rápida. Conocían sus dificultados para vencer a la marina y la aviación chilenas, debido a una paridad substancial; hubiera sido todavía más difícil atravesar los Andes e invadir el valle central de Chile, no solo por tratarse de terreno hostil sino también por la disciplina y la superioridad del Fiército chileno ${ }^{25}$. Los chilenos temían

Le Monde diplomatique, enero 1979.

$\therefore$ Pocos días después el subsecretario de agricultura norteamericano llego a Argentina y casi causó una crisis diplomática achido a gue al volar de Bucnos Aires a Ushuaia las turbulencias hicienron gute el avión ingresara al espacio acreo chileno. los servicios chilenos detectaron el avión cinterpretaron el hechocomo un señal de que Estados Unidos apoyaba a Argentina (Tapia, 1997: 239, 246).

$\therefore \quad$ Ios argentinos estaban al ataçue y no un ataque peruano o boliviano, y por ello mantenian la mayor parte de sus fuerzas en el norte: un ataque simultáneo de las fuerzas argentinas, peruanas y bolivianas -la Hipótesis Vecinal 3 (HV3)- siempre ha sido la pesadilla de los estrategas militares chilenos ${ }^{26}$. Por lo tanto, buscaron el apoyo brasileño: en el caso de una guerra general, Brasil habría intervenido en favor de Chile y, como fue confirmado en una entrevista con un oficial chileno de alto nivel, Brasil le vendió municiones, rifles y ametralladoras, cuando nadie vendía armas a Chile.

El día 20, el gobierno Chile invitó a Argentina a continuar las negociaciones y aceptar la mediación vaticana. A la mañana siguiente, los chilenos recibieron el rechazo argentino, formulado en un lenguaje extremadamente duro, que acusaba a Chile de intransigencia y falta de flexibilidad (Tapia, 1997: 161). Mientras tanto, Argentina redactaba la declaración de guerra y Chile recurría al Consejo Permanente de la Organización de los Estados Americanos. Ias

tenían la clásica superioridad de " 3 at 1 ", tradicionalmente considerada necesaria -en teoría militar-para invadir y ocupar un país.

2 "Un problema central en el planeamiento militar chileno es la HV3, csto es, la hipótesis de un conflicto contri tos tres países vecinos al mismo tiempo, es decir, lo que pasó a Paraguay a fines del mil ochocientos: los militares chilenos saben gue no pueden combatir en una misma guerra a tres enemigos" (Luis Maira, entrevista privada). 
dos fuerzas armadas se encontraban en pleno estado de alerta (Mares, 2001) ${ }^{17}$.

El mismo día, Videla informó a Laghi que si el Vaticano no intervenía de inmediato se iniciaría la guerra: "no estamos a días sino a horas" (Pastor, 1997: 265; Turolo, 1996: 119). Esa tarde el Nuncio envió un mensaje urgente a) Vaticano. El 21, el recién elegido Papa Juan Pablo II se dirigió al Colegio Cardenalicio ${ }^{2 x}$ y anunció que había designado un delegado, el Cardinal Antonio Samoré (Pastor, 1997: 265). Samoré se preparó para partir a Buenos Aires, primer paso a la mediación ${ }^{29}$. I. noticia llegó a mediodía a Buenos Aires y a Santiago. Chile aceptó de inmediato, mientras que la Junta Militar argentina se tomó todo el día para tomar una decisión.

Mientras las discusiones continuaban en Buenos Aires, el "reloj de la guerra" no paraba. A las 22 horas la Marina argentina atacaba y en el sur, las

Para una buena reconstruccion de los heches del campo de batalla, ver la pelicula Mi Mejor Fnemigo, dirigida por $A$ lex Bowen (2005).

ix Una transcripción parcial del texto figura en Tapia (1997: 168-169, 24()-248). Al mismo riempo, el Cardenal Raúl Silva Henrícuez también solicitó la intervención det Santo Padre (Videla Cifuentes, 2008).

Iu Tapia (1997: 168-171) narra los hechos del día del ataque, pintando la intervencion vaticana como tan "segundo milagro" ya que según sus palabras, el primero había sido una tormenta. El Vaticano intervino antes de la tormenta y fucron los propios argentinos los yue escogieron entre guerra y mediación. primeras tropas atravesaban la frontera con Chile. El mensaje de que "aviones... han detectado en la zonia de Cabo de Hornos, navegando en posición de ataque a la flota de guerra de la marina argentina" (Tapia, 1997: 16.3) se difundió en los altos mandos chilenos. Una inesperada tormenta estival impidió el ataque y el choque de las dos marinas fue providencialmente evitado.

Entre la tarde, noche y madrugada del 23, la Junta argentina decidió aceptar la mediación y los Comandantes de las tres fuerzas ordenaron movilizar las tropas. Argentina no podía sustentar los costos de una guerra total y Chile habia llamado el bluff.

Por un lado, los chilenos evitaron, a un costo relativamente bajo, una guerra que hasta habrian podido perder a un precio extremadamente alto; por el otro, Argentina reabrió las negociaciones, que no eran tan favorables a Chile como lo había sido el laudo británico. Amenazando la invasión, los militares argentinos consiguieron reabrir las negociaciones políticas, a través de una mediación que "ayuda a buscar una solución, pero no la impone" (Turolo, 1996: 119). Los argentinos debieron pagar, por la contraorden, el precio de cierto descrédito de los militares. Luego se estimó que la Operación Soberania costó al pás unos 3 mil millones". Al mismo tiempo, la segunda y más terrible crisis petrolera estaba por golpear a América Latina. No cabe duda que ambos países corrieron un riesgo enor-

3" Te Monde, 29 de diciembre de 1978 . 
me, sabiendo que no obtendrían relativamente nada. Estos eventos pudieron fácilmente provocar una guerra, pero no lo hicieron, casi por casualidad.

\section{De la casi-guerra a la mediación} Del 2.3 de diciembre de 1978 al 2.5 de marzo de 1980

La noticia de la mediación papal y de su acentación por ambos lados dio una sensación de triunfo (Turolo, 1996: 125), especialmente en Buenos Aires. El 27 de diciembre de 1978, según Samoré, cn ambos países la vida tenía un ritmo casi normal (Tapia, 1997: 178). Al encontrarse con Videla y Pastor, Samoré preguntó si realmente no había "ni una lucecita de esperanza" para resolver la disputa y cuál era el resultado mínimo que se podía aceptar. "Una línea con asentamientos en tierra firme que frenara definitivamente los intentos de expansión chilena en el Océano Atlánticon, fue la respuesta de los argentinos (Turolo, 1996: 121). Argentina pidió a Laghi que firmara un documento en que se declaraba que Samoré había entendido la posición argentina y que él la habría comunicado al Papa. En Bucnos Aires, Samoré habló con Videla, Pastor y Laghi, así como con la Junta. Según Pastor (1996: 266), Samoré estaba convencido de que Argentina y Chile eran como un "bife de chorizo" con toda la carne del lado argentino. Fl 28, Samoré viajó a Chile donde confesó a Cubillos que su "misión no tenía ninguna posibilidad de éxito debido a la rigidez e inflexibilidad" de Chile (Tapia, 1997: 179).

Pastor recuerda que al volver a Argentina Samoré "regresó desanimado $y$ hasta asustado por la severidad con que lo tratan y la inflexibilidad de sus interlocutores" (1996: 266). Chile no tenía nada que perder con su rigidez. En Buenos Aires, los argentinos pidieron que les diera una garantía de que sus legítimas reclamaciones scrian respetadas. Fsto molestó a algunos negociadores, inclusive a Pastor, quien envió emisarios, de manera privada, tanto a Laghi como a Samoré, pidiéndoles que hicieran algo por calmar los espíritus $(1996,266)$. "No hay más remedio que rechazar el laudo, o impedir, de toda forma posible, que el gobierno chileno extienda sus pretensiones del otro lado del Cabo de Hornos hacia el Atlántico" comentaba el diario bonaerense La Opinión ${ }^{31}$, mientras el ex presidente Levingston declaraba: "La integridad de la nación será preservada a cualquier precio y esta es una obligación internacional no negociable" ${ }^{32}$. Para muchos, la guerra era todavía una opción.

Samoré viajó a Santiago y de vuelta a Buenos Aires trató de persuadir a ambos lados que firmaran un acuerdo que permitiera la mediación. Desde el principio, en sus propias palabras, wen Chile había un muro, mientras que en Argentina, nunca sabía quién era el interlocutor ni qué querían". Un negociador argentino testimonió: «A

"7 de enero de 1979 .

: Fl Nercurio, 8 de enero de 1979. 
pesar de que Samoré negociaba con el Presidente, siempre este último recibía sugerencias de la Marina... Cada fuerza seguía su lógica y quería prevalecer. Era una cuestión de prestigion.3.3.

El acuerdo de mediación, también conocido como "Acta de Montevideo", fue firmado el 8 de enero de 1979. El acuerdo tenía dos partes: la solicitud de mediación y el texto del acuerdo, así como el compromiso de los dos lados de "resolver un diferendo a través de la mediación" (Acta, 1979: párr. 11; Fogg, 1983:268; Passarelli, 1998: 276), en otras palabras, no producir ningún hecho militar (Pastor, 1996: 267). Inicialmente las partes querían publicar sólo la primera parte del acuerdo ad scandalum vitandum. Cubillos se negó a firmar un pacto secreto y las partes acordaron hacer pública la totalidad de texto del acuerdo (Tapia, 1997; Pastor, 1996: 267).

El 24 de enero, Juan Pablo II aceptó oficialmente la mediación y en febrero, durante su visita a México, anunció que las negociaciones estaban listas. En abril, ambos lados nombraron a sus respectivos negociadores: Enrique Bernstein, un diplomático experto, por Chile, y Guillermo Moncayo, un jurista, por Argentina (Tapia, 1997, 201). Originalmente el lúcido Pedro Frías asistia a Moncayo, mientras detrás de Bernstein se celaba el General Ricardo

:2 Entrevista reservada; ver tambien la entrevista de (ubillos en Tapra (1997: 202).
Etcheverri Boneo, los "ojos y oídos" de los militares ${ }^{34}$.

El 23 de abril se celebró en Roma el primer encuentro (Benadava, 1999; Pastor, 1996: 268). Al principio, Samoré evitó referirse a las cuestiones más contenciosas, concentrándose en crear confianza entre las partes. Para los dos países, la estructura de las negociaciones era aproximadamente la misma: los negociadores de Argentina recibian instrucciones directamente de la Junta y los de Chile las recibian de Pinochet. Las delegaciones rendían informes periódicos a los respectivos ministerios de relaciones extcriores. Chile se mantuvo inflexible y Argentina mostró varias caras ${ }^{35}$ lo que reducía su poder de negociación-. A mediados de 1979 los negociadores recordaron que "el mediador ayuda y guía para encontrar

is Mientras tanto, el 21 de marzo de 1979 Cubillos había sido reemplazado por René Rojas (ialdames como Ministro de Relaciones lixteriores de (hile, a raí del tracaso de la visita de p'inocher a Filipinas (Tapia, 1997: 209).

Fl rector honorario de la Universidad Católica de Argentina, Mlonseñor Octavios Derisi, recuerda que Cubillos era de las palomas, mientras que del lado argentino, el Secretario del Fijército, general Reinaldo Bignone, y el Secretario de la Aviación, general Brigadier Basilio Lami, eran de los halcones, sin considerar yue más tarde sería Comandante en lefe del lijercito el tenicnte general l copoldo (ialtieri, considerado como al "duro entre los duros" (Tapia, 1997: 20.3-205). "Pinochet tenia algunas diferencias de forma y fondo con otros miembros de las luersas Armadias", pero nada comparable con lo yue alcontecía en Bueness Aires (210). 
una solución, pero no es un árbitro"; en julio Chile presentó su documentación (Tapia, 1997: 200), y Argentina lo hizo en seguida, denunciando la manipulación de los mapas ${ }^{3 \pi}$. Entretando, Samoré dijo: "Los argentinos no me entregaron un solo mapa anterior a 1955, uno solo, probatorio de que las Islas Nueva, Lennox y Picton estaban bajo su soberanían(203).

Las negociaciones a menudo se tornaban tensas y en varias ocasiones Samoré tuvo que recordar a las partes su compromiso moral. Por esta razón, en septiembre los negociadores optaron para una "pausa de reflexión". A mediados de 1980, finalmente los negociadores enfrentaron las cuestiones más delicadas, es decir, las respectivas pretensiones territoriales. Antes del mes de novicmbre, el Vaticano presentó una propuesta de acuerdo. La posición de los argentinos en las negociaciones era bastante frágil. A diferencia de Chile, nunca habian ocupado efectivamente las islas. El Vaticano percibia Argentina como rica y Chile como pobre: "hay que dar más al que tiene menos". Además, algunos mapas oficiales argentinos mostraban las islas del Canal de Beagle bajo jurisdicción chilena (Pastor, 1996: 269). Samoré pensó que, si bien Argentina no tenía derecho a ganar

Tras comparar los mapas originales de los Archivos Nacionlales en Buenos Aires y Santiago, el historiador argentino Pablo lacoste afirmó çue varios mapas fueron adulterados y que los argentinos escondicron todos los mapas que confirmakan la versión chilena. tierra, podría pretender ser compensada con mar (Turolo, 1996: 123). Además, percibió que Argentina, -desde su posición de fragilidad- nunca habría aceptado una solución no favorable. Asimismo, a finales del año se produjo el primero de una serie de incidentes en clara violación del Acta de Montevideo: un caso de espionaje militar chileno en la provincia de Santa $\mathrm{Cruz}^{37}$ (Tapia, 1997: 204).

El 12 de diciembre, el Santo Padre hizo pública solemnemente su propuesta, muy semejante al laudo británico. Se dejaban las islas y los derechos marítimos limitados a Chile, creando el así dicho "Mar de Paz" fuera del area disputada. El Papa se refirió a la propuesta como:

Justa, porque desde el punto de vista jurídico no se podia apoyar la pretensión argentina en cuanto a posesiones terrestres; ecuánime, porque, en compensación de la tierra que no daba a la Argentinil, Ic entregaba una gran extensión de mar; honorable, porque todos hablían salido bien del problema ${ }^{3 \times}$.

A los argentinos no les gustaba esta solución, pero tenían que aceptarla no solo por su débil posición en las negociaciones, sino por la frágil situación de Videla a fines de 1980 -que también debería enfrentar a Pinochet, que acababa de ser confirmado como Jefe de Estado por los diez años siguientes como consecuencia de la nueva constitución y del

\footnotetext{
Vease supra.

is Turolo (1996: 123).
} 
plebiscito-, y de la creciente crisis económica y financiera (Escudé-Cisneros, 1998-2003). Chile aceptó la propuesta de inmediato y de manera entusiasta; Argentina no perdia nada rechazándola. El 25 de marzo, tres días antes de que Videla perdiese la presidencia de la Nación, Argentina anunció pública y oficialmente el rechazo de esta primera propuesta papal.

Después del diferendo territorial y la casi-guerra, las negociaciones se alejaron del debate político; en Argentina adquiría importancia el acercamiento con Brasil respecto de la presa de Corpus/Itaipú y la situación económica cada vez más problemática ${ }^{34}$. Las negociaciones adquirieron dinámica propia y tanto en las agendas y como en la prensa de ambos países queda. ron bajo la sombra de cuestiones más urgentes. Los intercambios vecinales entre Argentina y Chile se normalizaron relativamente, pero a un nivel inferior, en comparación con el periodo anterior a la crisis.

Las nuevas negociaciones y la guerra de las Malvinas

Del 25 de marzo de 1980 basta el verano de 1982

El 29 de abril, después de otro episodio de espionaje chileno, la caída de

Pocos dias antes del rechazo, cl fraciaso del Banco de Intercambio Regional marcó los comienzos de la crisis banciaria de marzo de 1980 .
Videla y la instalación de Violat(1), las fronteras volvieron a cerrarse (Memorias, 1981: 11; Escudé-Cisneros, 19982003). Bajo Viola, las negociaciones en el Vaticano no avanzaron. Mientras tanto, Oscar Camillón, el delegado para las relaciones exteriores, intentó sin éxito alguno relanzar el proceso negociador (Russell, 1996: 315). La razón fundamental de este fracaso se explica no solo por la persistencia de sectores favorables a una solución armada del diferendo en los paises y gobiernos, sino también porque la crisis económica ocupaba el primer lugar en la agenda de los dos gobiernos y porque los crecientes fenómenos de espionaje (Memorias, 1981) estaban generando más interés que las negociaciones vaticanas (Tapia, 1997: 204).

En diciembre de 1981, Galtieri accedió al poder en Argentina ${ }^{+1}$. Según un antiguo diplomático chileno, él fue uel dictador más estúpido que Argentina pudo tener". El Tratado General de Arbitraje de 1972 terminaba el 27 de diciembre de 1982 y Argentina había decidido no renovarlo, por lo que a Chile le habría sido imposible recurrir unilateralmente a la Corte Internacional de Justicia. Por la tanto, la mediación papal era la única manera de conseguir un acuerdo. Nuevos episodios de espionaje y de violaciones territoriales

4: Rolerto Viola fue presidente de Argentina del 29 de marro al 11 de diciembre de 1981.

+ Iccopoldo Gialtieri ocupó la presidencia del 22 de diciombre de 1981 al 18 de junio de 1982. 
perturbaron las relaciones diplomáticas bilaterales (Memorias, 1982: 22-24). En Argentina, las turbulencias económicas, el populismo de Galtieri y de la Multipartidaria -coalición de partidos de oposición-, llevaron a la ocupación de las Malvinas el 2 de abril de 1982 (Pastor, 1997: 270-281; Moneta, 1982 y 1984; Freedman, 2005). El mismo dia, Cralticri anunció a la nación que la ocupación de las islas era el "premier paso para recuperar los territorios históricamente argentinos" ${ }^{42}$.

¿Fsta declaración de Galtieri implicaba también los diferendos territoriales con Chile o solo las Islas Malvinas? El rechazo del Tratado de 1972, las violaciones territoriales, la ocupación de las Malvinas y la reclamación de los territorios históricos preocuparon a Chile. Los líderes argentinos lo sabían. Por una parte, temían que los chilenos pudieran aprovechar esta situación para invadirlos, por lo que dejaron la mayoría de sus tropas en las fronteras con Chile y, según el experto en relaciones entre civiles y militares, Andrés Fontana, Argentina cavó trincheras para permitir a los tanques dirigirse hacia Chile y no hacia las Malvinas ${ }^{43}$. Por otra parte, los chilenos temían ser los próximos en la lista. Pinochet comentó:

Optaron por comenzar el conflicto con Inglaterra, creyendo ganarle muy pronto para enseguida atacar a (hile ... Craltieri no penso jamí́s que los

4: Iat Nacion, 3 de aluril de 1982.

4: Fintrevista privada. britinicos cruzarian el Atlántico para recuperar las islas ${ }^{34}$.

Según las palabras de un general chileno $^{+5}$, cuando Thatcher decidió recuperar las islas, la "neutralidad favorable de Chile y su esperanza de una victoria británica estaba justificada". Argentina reaccionó mal a la neutralidad favorable chilena, tanto en las $\mathrm{Na}$ ciones Unidas como en la Organización de los Estados Americanos ${ }^{46}$.

La guerra de las Malvinas quedó como una herida abierta para Argentina -con unas fuerzas armadas "fracasadas" $y$ sin prestigio alguno, y con relaciones deterioradas con Chile.

La transición argentina y el Tratado de Paz y Amistad

Desde el verano de 1982 hasta la primavera de 1984

Demostrando otra vez su autonomía relativa, el 23 de abril de 1982 se

4. Clarim, 26 de noviembre de 1999.

th Entrevista reservada.

th Al interior de la Organización de los Fistados Americanos, (hile junto onn los Estados Inidos y pocos países más se abstuvieron de votar la resolución que autorizaha la intervención en el contlicto anglo-argentino en el marco ded Tratado Interamericano de Asistencia Recíproca de 1947. I a oposición de varios sectores de la población chilena a la neutralidad favorable contribuveron a la progresiva evolución de la posición del gobierno chileno bacia Argentina especialmente en cl contexto de las Naciones Unidas (tiscutdé-Cisnteros, 1998-200.3). 
reanudaron las negociaciones en medio de la crisis de las Malvinas (Mares, 2001). El $1^{\circ}$ de junio, Bignonet remplazó al humillado Galtieri. Bignone declaró prontamente que cualquiera que fuera el resultado de las negociaciones, este debería de ser aprobado por el Congreso argentino. Samoré se encontró frente al desafío de persuadir a Argentina de renovar el Tratado General de Arbitraje. Mientras tanto, el Vaticano recomendó a Chile que presentara unilateralmente el caso a la Corte Internacional de Justicia, para no perder el derecho de hacerlo. El 28 de julio, Samoré presentó a las partes un documentots y les pidió que aceptaran la invitación papal a renovar el Tratado y congelaran el diferendo unos años ${ }^{49}$. El 10 de septiembre, los dos países aceptaron la propuesta y renovaron el Tratado. F.l 15 del mismo mes, firmaron el Acuerdo de Ciudad del Vaticano y acordaron renovar el Tratado General de Arbitraje (Lanari, 1996: 336-339). ¿Por qué Argentina aceptó renovar el Tratado si no estaba obligada a hacerlo? Si Chile presentaba otro caso, Argentina habría perdido nuevamente. Argentina decidió conceder algo a fin de sentar un precedente que obligaba a Chile hacer otro tanto.

El 3 de febrero de 1983 falleció el paciente Samoré y fue reemplazado por

4. Reynaldo Bignone fue presidente de Argentina del $1 "$ de julio de 1982 al $10 \mathrm{de}$ diciembre de 1983.

is Doc. Vat. 3/82.

4- Dor. Vate. 4/82. el influyente Casaroli" . Este percibió que algo estaba cambiando del lado argentino" debido a la crisis económica y sobretodo por el término gradual del régimen militar e insistió en que se firmara un tratado parcial. Samoré había postulado esta propuesta en septiembre de 1982 y el 8 de junio de 1983 Casaroli la formulo nuevamente. Sin embargo, el Vaticano estaba intentando congelar el diferendo (Lanari, 1996: 339; Mares, 2001; Domíngue', $2003)^{52}$. Chile era partidario de congelarlo, mientras que Argentina insistía en una solución definitiva, visto que la mayoría de las cuestiones estaban solucionadas y que el congelamiento solo podría producir nuevas fricciones en un futuro proximo. El 17 de agosto, Argentina rechazó el tratado parcial. Según el negociador chileno Benadava "la mediación seguía letárgica" (1999: $125)^{53}$. En julio, el mismo Bendava se

5: Fl Sceretario de Fstado Agostino (Casaroli cra muy cercano al papa juan Pablo II y al Cardinal Sodanos. Según Kissinger, fue el diplomation más inteligente yue haya conocido (Benadava, 1999: 12.5).

"Según Benladiava (1999: 128) entre marzo y mayo de 198.3, meses inmediatimente anteriores a las cleciones presidenciales, el Vatticano intentó sin exito insistir con Buenos Aires para encontrar uial solución al diferende.

i2 Para Benadava (1999: 128) fue el golvierno militar argentino el que intentó congelar las negociaciones. Los documentos oficiales y la precisión de la reconstrucción de Lanari (1996: 3.39) hacen más verosímil la versión anterior.

"Un chiste publiciluo en FI Mercurio (198.3) decia así: "I le encontrado... trabajo en la delegasión chilena ante la mediación... No 
encontró con Barberis ${ }^{54}$ en la Academia de Derecho Internacional de La Haya. F.n las denominadas "conversaciones B-B" se discutió la propuesta papal de diciembre de 1980 (133-135). Esta actitud confirma la autonomía relativa de los negociadores argentinos, tanto juristas como militares, de lo que acontecía en Buenos Aires. Es importante señalar las dificultades que experimentaba en aquel entonces la delegación argentina, compuesta de funcionarios civiles y militares, estos últimos con luchas continuas entre sí debido a la pérdicla de credibilidad después de los acontecimientos de las Malvinas. Para un militar no hay nadia peor que ser vencido.

Los últimos meses de 1983 fueron meses de cambio en Argentina. Los militares habian prometido nuevas clecciones para principios de año; en octubre Alfonsín ganó las elecciones presidenciales, para sorpresa de todos (Morales, 1992). Hahía comenzado la "transición hacia la democracia". Alfonsín asumió el poder el 10 de diciembre de 1983, con la economía en ruinas, un aparato del Estado totalmente ineficiente y el fracaso de los militares. La economía chilena también sufría, pero Pinochet parecía fuerte e inmutable. Las partes se aproximaron a un acuerdo e intercambiaron informes y propuestas cada vez más constructivos

pagan mucho, pero es un trabajo para la vida...."

ifulio Barberis, jurista internacional y micmbro del equipo negociador argentino. y exhaustivos" (Lanari, 1996:340). En rigor, los avances tenían más que ver con la inercia de las negociaciones, el trabajo individual de los negociadores y las dinámicas internas de las delegaciones, que con los cambios políticos en Argentina.

La nueva Administración se instaló en Buenos Aires y Alfonsín nombró Canciller a Dante Caputo ${ }^{56}$. El nuevo equipo negociador de Argentina fue dirigido por el Embajador Gobbi y el profesor Delpech, que continuaron la labor de sus predecesores con el objetivo de llegar a una conclusión rápida y honorable. Las dos prioridades de la administración de la Unión Cívica Radical eran mejorar las condiciones económicas e impedir el retorno de los militares al poder. Resolver la disputa con Chile habría "cortado las piernas a los militares", como comentó en una entrevista privada un experto argentino. Los militares podían utilizar la disputa para convencer a los nacionalistas de actuar contra el nuevo gobierno (Fournier, 1999: 63). Además, resolver el diferendo era una manera de reconquistar la confianza de los inversionistas extranjeros. Finalmente, profundizar la integración con Chile formaba parte de una nueva política exterior argentina, basada en "la democracia, los derechos humanos y la justicia social» (Torres,

"5 Véase, por ejemplo, el informe del negociador chilemo Ftcheverry Bones al gobierno) argentino, de novicmbre 1983.

in Sociólogo y politólogo radical. Estudió cul Francia y miraba más hacia Europa gue hacia listados Unidos. 
2002: 129; Alconada, 1996: 345-354; Caputo-Sábato, 1991: 194-208). F.l nuevo gobierno sostuvo consultas con muchos de los exiliados chilenos que habian vuelto a Argentina después de 1983, razón, por la cual no acusaron a Alfonsín y a Caputo de una actitud aparentemente conciliadora con el régimen pinochetista ${ }^{57}$.

Durante el verano de 1984, los negociadores finalmente resolvieron las últimas cuestiones contenciosas (Benadava, 1999: 143-148). Respecto del mar, el mediador aconsejó una línea casi idéntica al laudo británico. $\mathrm{La}$ propuesta asignó las tres islas a Chile; amplió de tres a seis millas el territorio chileno alrededor del Cabo de $\mathrm{H}$ lornos; extendió la zona económica exclusiva de ambos países (Infante, 1987); y redujo la proyección marítima de las islas de Chile situadas más al sur (Pinochet de la Barra, 1987 y 1999). I.os dos lados aceptaron rápidamente el compromiso.

Las partes concordaron también un nuevo mecanismo para la solución de controversias (Anexo I) y para la determinación de los derechos de navegación (Anexo II), afinando lo que ya habían convenido. La propuesta del mediador incluyó la creación de una "comisión

Para una perspectiva positiva de la acción de Argentinil, ver por ejemplo el artículo del entonces Secretario Cieneral del Novimiento de Acción Popular Unitaria (MAPU), el sociólogo Oscar Garretón (1985); para un vision opuesta, ver el artículo que apareción en la publicación socialista Unidad y Lucha de noviembre de 1984. binacional" para la resolución de asuntos económicos (articulo 12). Fl 4 de octubre, los negociadores anunciaron que habian conseguido un acuerdo y el 18 del mismo mes se entregaron a las partes las copias originales de los resultados de la mediación. Inicialmente sc habia escogido el 24 de noviembre como fecha para firmar el acuerdo que entraría en los anales de la historia como el "Tratado de Paz y Amistad" (Lavopa, 1995: 188-209; Díaz Albonico, 1987). Pero Argentina pidió que el preámbulo mencionara el principio bioceánico, por el cual la firma se retardó al 29 de noviembre.

Casi cinco años fueron necesarios para que los representantes del gobierno militar pudiesen llegar a un acuerdo. ¿Por qué al equipo negociador de Alfonsín requirió solo un año? Según Fontana, cl acuerdo era un producto de la mediación papal, que tomó poco tiempo a los radicales de conseguir debido a que "sobre la mesa permanecían pocas cuestiones" ${ }^{58}$. La tesis de Fontana parece coincidir con la información disponible al respecto, ya que es muy probable que la determinación política de los radicales pudiera catalizar las negociaciones.

El 20 de octubre el gobiemo chileno anunció el acuerdo a través de la televisión nacional. El pueblo chileno dio la bienvenida a la noticia y pocos fueron los descontentos (Benadava, 1999: 149). A fines de 1984 Chile vivía una profunda crisis económica y se

\footnotetext{
a* Entrevista privada, mayo de 2005.
} 
encontraba solo y sin aliados debido a su régimen político y a la situación de los derechos humanos ${ }^{54}$. Por ello, buscó una nueva inserción en la región y en la economía global, la segunda de las cuales concretó en las reformas de Büchi de $1985^{\text {th }}$, y la primera mediante la solución del diferendo con Argentina sobre el Beagle. El 11 de abril de 1985 , la junta militar chilena ratificó el tratado (Lavopa, 1995: 33).

La Administración Alfonsín tuvo que enfrentar uno de los debates públicos más polémicos de la historia, ya que se relacionaba al mismo tiempocon la gestión económica del país y con el juzgamiento de los actores del régimen militar. Varios sectores del pais, en particular las elites políticas, rechazaron el tratado, ya que-como decía el antiguo Presidente Levingston- "permite la penetración chilena en el Atlántico"61 (Benadava, 1999: 150; Lavopa, 1995: 3.3). A mediados de marzo, el Senado, dominado por los justicialistas, aprobó el tratado por el estrecho margen de 23 a 22 (Russell, 1990: 54-68; Fscudé(isneros, 1998-2003). El 26 de julio, los radicales llamaron a un referéndum para obligar a los críticos del tratado a exponerse publicamente (Lavopa, 1995: 182-187). El 15 de noviembre,

Los Fstados Unidos temían que C'hile se comvirtiera en una nueva Nicaragua a través de la crisis económica de 1982 y a la profunda desiguaklad social (Fermandois, 1991).

\#. Itrman Bïchi, ministro de conomía de 1985 a 1989.

La Nación, 22 de agosto de 1994. el líder de la oposición peronista"2, Vincente Saadi, enfrentaba a Caputo en el primer debate televisivo de la nueva democracia. La «serena racionalidad" de Caputo prevaleció sobre la «retórica explosiva" de Saadi ${ }^{63}$ y el 25 del mismo mes el $81 \%$ de los argentinos votó en favor del tratado ${ }^{64}$. La Administración radical consiguió acallar a los militares y a la oposición. El 26 de marzo el gobierno argentino ratificó el Tratado de Paz y Amistad.

Con la ratificación argentina del Tratado, los dos países dieron fin al primero de los veintiséis diferendos territoriales que quedaban pendientes desde el principio del siglo, entre los cuales destacaban los de la Laguna del Desierto, Campos de Hielo Sur y cuestión Antártica. L a presente reconstrucción de este momento determinante de las relaciones transandinas permite apreciar cómo hace treinta años Argen-

$\therefore$ Los anos ochenta fueron una década difícil debido al auroritarismo, cl nacionalismo, la doctrina social de la lglesia y el sindicalismo, cuatro elementos que constituyen el peronismo tradicional. Los peronistas fueron relegados a la clandestinidad por casi una década y perdieron las elecciones presidenciales y el referéndum. Solo ma minoria del l'artido Justicialista, encahezada por Bordón, entonces diputado, mas tarde gobernador de Mendoza, y por Menem, entonces gobernador de La Riojal, estaha a favor del tratado. Cabe scrialar que tanto el electorado de Bordón como de Menem se encontraban on la frontera con Chilc.

* La Nacion, 15 de noviembre de 2004.

in Para un estudio interesante sobre los resultado del reteréndum, ver Lacoste (1998: 1.3.3). 
tina y Chile casi recurrieron a la fuerza militar para resolver la disputa por el Canal Beagle, diferendo que al final resolvieron pacífica y amistosamente.

La solución pacífica de la crisis ocasionada principalmente por la agresividad de algunos dirigentes argentinos y por la inflexibilidad del lado chileno sobre unos intereses estratégicos y políticos comunes, fue posible gracias a la perseverancia y la paciencia de algunos protagonistas de ambos lados, a la coyuntura política y económica de la época y también a las coincidencias de la historia. La crisis del Canal de Bengle dio a conocer a las clases dirigentes de los dos países las ventajas y defectos de varias modalidades de arreglo de diferencias territoriales: del recurso al arbitraje internacional a las negociaciones políticas, de la amenaza de guerra a la mediación, favoreciendo la solución pacifica de los otros veinticinoo diferendos territoriales.

Sin pretender representar la historia "definitiva" de la crisis del Canal de Beagle», esta reconstrucción no se limita a recoger las memorias de unos cuantos protagonistas de la época.

Incluye tanto relatos de militares, civiles y religiosos de ambos lados como entrevistas inéditas y análisis de expertos y académicos, con el fin de tratar de destacar la complejidad del periodo. Procura fomentar una interpretación que contribuya a dar a luz sobre un episodio tan oscuro en la historia de las relaciones entre Chile y Argentina, antes de la tan esperada apertura de los archivos nacionales tanto en Buenos Aires como en Santiago.
En tan solo dos décadas Chile y Argentina lograron pasar de una casi guerra a una integración ejemplar, por lo que el tema apasiona a investigatores de todo el mundo. No sorprende el reciente florecer de contribuciones científicas al análisis de estas relaciones especiales.

\section{BIBLIOGRÁFIA}

Act of Montevideo by which (bill and Argentima request the Holy See to act as a medator with regard to the ir dispute oter the Sonthern region and andertake not to resent to force in their mutual relations (with supplenentaly dedantion)(1979), United Nations Treaty Series, vol. 11.37, $11^{\circ} 1-17838$.

Aguiare 1.anari, J.R. (1996), "Unal Ruta Transitahle", Ia politica exterior argentinay su protagonistas, $1880-1995, \mathrm{Jal}$ abe, S.R. (ed.), Buenos Aires, CARI, pp. 32.3-34.3. Alconadia Sempé, R. (1996), "Democracial y Polítical Exterior", co la politica exterior argentinal y st protagenistas, 1880-1995, Jalabe, S.R. (ed.), Buenos Aires, (ARI, pp. $34.5-35.5$.

Arancibia Clavel P. c Isable de la Mara Cave (200)3), Mathei. Mi testimonios, I al Tercera-Mondiactori.

Auard of Her Britannic Malesty's (ioleentment pursuant to the Agreenent for the Arbitration of a Contrenersy between the Argentine Republic and the Republic of Chile concerning the Region of the Beagle (bannel (1977), londres, Her Majesty's Stationery (Office.

Benadava, S. (1999), Recuerdos de la mediatción pontificia entre Chile y drgentina, 1978-1985, Santiago, Fditorial Universitaria.

Bignone, R.B.A. (1992), HI Ultimo de Facto: la liquidacion del proceso: memoria y testimonio, Buenos Aires, Planetil. 
(aputo, I)., y. Sábato (1991), "Perspectivas de la lntegración político-Fconómica Continental. Ial Integración de las I emocracias Pobres: ()portunidiades y Peligros", cn Estudios Internacionales, vol. XXIV, 11. 94, pp. 124-208.

Child, I. (1979), "Geopolitical Thinking in latin America", en latin American Researd Revicu, vol. 14, n. 2, pp. 89-111.

Cox, R. (1980), The Sound of One Hand Clapping: A Preliminary Study of the Argentine Press in a Time of Terror, Washington, Woodrow Wilson Internationial Centre for Scholars.

Díaz Alhonico, R. (ed.) (1987), Fl Tratado de I'az y Amistad entre (bile y' Argentina, Santiago, Editorial Iniversitaria.

Dominguez, J.I., D. Mares, M. Orozeo, D.S. Palmer, F. Rojas Aravena y A. Serbin (200)3), "Boundary Disputes in Iatin America", Peacentorks, n. 50 .

Ficudi, C., y A. Cisneros (1998-200)3), Historia general de las relaciones exteriores do la Republica Argentina, Buenos Aires, Grupo Editor Latinoamericano.

Fermantlois, J. (1991), "De una inserción a la otra: lolitica exterior de Chile 19661991", en Fstudios Internacionales, XXIV, n. 96, pp. 433-455.

Fogg, G. (1983), Soberania Argentind en el Area Alustral, Buenos Aires, Meamar.

Fontana, A. (1990), la politica militar e'n an contexto de transicion argentina, 19831989 , Buenos Nires, CEIDF.S.

Fontana, A. (1990), Percepción de amenazas $y$ adquisicion de armamentos: Argentina 1960-1989, Buenos Aires, (.FI)FS.

Fourmer, 1). (1999), "The Alfonsin Administration and the Promotion of 1 )emocratic Values in the Southern Cone and the Andes", fournal of latin American Studies, vol. 31, n. 1, pp. 39-74.

Freedman, L. (2005), The ()fficial History of the lalklunds Campaign, Nucva York, Routledge.

(ratretom, (). (1985), "Una Opinion Chilena deste Argentina "A La Moneda, vol.1, n. 1 , pp. 15-16.
Garrett, J.I. (1985), "The Beagle Channel Dispute, Confrontation and Negotiation in the Southern cone", en Journal of Interamerican Studies and World Affairs, vol. $27,11.3$, pp. $81-109$.

(iomez. Rueda, 1 1. (1977), Tenray doctrina de la Geopolitica, Buenos Aires, Astrea.

(iuzman (iuticrrez, J. (2004), The Antarctic Tradition of Chile. An Historical Re'icu': 1540-1991, University of Cambridge, Centre of I atin American Studies.

Infante (affi, M.'T. (1984), "Argentina y Chile: percepciones del conflicto de la zona del Beagle», en tistudios Internacionales, XVII, 13. 67, Pp. 3.37-3.58.

Kelly, l., y J. Child (1988), Geopolitics, Integration, and Conflict in the Southern Cone and Antarctica, Londres, Lyme Rienner.

Knudson, J.W. (1997), "Veil of Silence: The Argentine l'ress and the Dirty War, 19761983", cn Iatin American Perspectives, vol. 24, n. 6, pp. 93-112.

Lacoste, P. (1998), El Sistema Pelunenche: Frontera, sociedady camines en los Andes Centrales argentine-chilenos (16.54-1997), Gobierno de N1cndoza, Universidad Nacional de Mendoza, Facultad de Ciencias Políticas y Sociales.

Lacoste, I'. (200.3), la imagen del otro en las relaciones de la Argentina y Chile (1.5.3420(0)), Buenos Mires, Fiditorial Fondo de Cultura Fconomica - Universidad de Santiago de Chile.

Lavopa, J.H. (ed.) (1995), Las relaciones argentine-chilenas. Politica economica. exterior y de defensa. I a intluencia de los grupos de presión desde el Tratado de Paz $y$ Amistad de 1984, Buenos Aires, CARIFundación Konrad Adenaner.

Madrid Muría, R. (2003), "la Fstrategia Naciomal y Militar yue planificó Argentina, en el marco de una estrategia total, para enfrentar el conflicto con Chile el ano 1978", Memorial del Ejercito de Chile, Santiango, n. 471.

Menorias del Ministerie de Relaciones Fixteriores (1976-1997), Santiago, Ministerio de Relaciones Fxteriores. 
Jon Marco ChURCH - La crisis del canal de Beagle

Menéndez, I.B. (1981), Asipiensa... I.uciano B. Menendez, Buenos Aires, Nemont.

Miranda, P.N. (1989), Terrorismo de Fistado: Testimomios del Herror en Cille y drgentina, Santiago, Fixpediente Negro.

Moneta, C.J. (1982), "Fl conflicto de las lslas Malvinas: su papel en la política exterior argentina y en contexto mundial ", Fistudios Internacionales, 17. 60, pp. 361-409.

Nieneta, C.J.(1984), "The Malvinas Conflict: Some Elements for an Analysis of the Argentine Military Regime's DecisionMaking Process", en Mluñoz, H., y J.S. Tulchin (eds.), Iatin American Nations in World Politics, Boulder, Westview, pp. 128-129.

Morales Sola, J. (1992), Asalto a la Mhision: bistoria secreta del perder en la Argentina desde 1983, Buenos Aires, Planeta, 9a ed.

paredes, A. (2004), "La (operación Condory la gierra fría", en [innersum, 11. 19, vol. 1, $122-1.37$.

Passarelli, B. (1998), El Delirio Armado. Argentina-Chile: la guerra que evitó el Papa, Buenos Aires, Sudanericana.

Pastor, (..W. (1996), "Chile: la (iucra o la P'az, 1978-1981", en Jalabe, S.R. (ed.), I.a politica exterior argentina $y$ su protagomistas, 1880-1995, Buenos Aires, C.ARI, p). 2.59-308.

P'inochet de la Barra, (). (1987), "I a Antártica y cl Tratado de laz y Amistad", en El Tratade de Paz y Amistad entre Chile y Argentina, Diaz Albonico, R., (ed.), Santiago, Editorial Universitaria, pp. 125-128.

l'inochet de la Barra, (). (1999), (bile y Argentina en la Antártica. Algunas Reflexiones, Buenos Aires, CARI.

Pimocher Ugarte, A. (1474), Geopolitica, Santiago, Andrés Bello.
Princen, T:1. (1988), "Beagle (hannel Negotiations", en Case Studies in Interhational A/fairs, 11.401.

Rojas, L.F, y A. Medrano (1979), Argentina en el Atlintion (bile en el Pacifico, Busans Aires, Nemont.

Russell, R. (1990), "El Proceso de toma de decisiones en la política exterior argentina", en Politica kixterior y H:I Procesos de Toma de Decisiones en Amorica Latina, Russell, R., (tel.), Buenos Aires, (irupo Editorial I atinoamericano.

Russell, R. (1996), "Narthas y Contramarchas de la Politica Fixterior del proceso: Los Gobiernos de Viola, Craltieri y Bignone, 1981-1983", en Jalabe, S.R. (cd.), la politica exterior argentina y su protigonistas, 1880-1995, Bucnos Aires, CARI, pp. $309-321$.

Seoane, M. y V. Mlulciro (2001), Hl Dictador: La bistoria secreta y puiblica de Jorge Rafal Videlar, Buenos Aires, Sudamericana.

Tapia, I..A. (1997), Estan hodre: la guema, Viña del Mar, Universidad Maritima de (hile.

Torres, M.A. (2002), "El Proceso de Integración Latinoamericano en el Discurso cel l'residente Alfonsín (1983-1989)", (n) Revista de Fstudios Fransindinos, n. 7 , Pp. 115-131.

Treaty of Peace and Friendship betuee'n atrge'ntina and Chile (1984), United Nations.

Turolo, (..M1. (1996), De lsabela Videla, Buenos Aires, Sudamericana, pp. 111-134.

Videla Cifuentes, E. (2008), la desconocida bistoria de la Mediacion Papal, Santiago, Universidad Carólica de Chile.

Yofre, J.B. (2000), Misión argentina en Chile, 1970-197.3, Providencia, Sudamericana. 